\title{
Modes and nodes explain the mechanism of action of vortioxetine, a multimodal agent (MMA): modifying serotonin's downstream effects on glutamate and GABA (gamma amino butyric acid) release
}

\author{
Stephen M. Stahl \\ ISSUE: \\ Vortioxetine is an antidepressant with multiple pharmacologic modes of action at \\ targets where serotonin neurons connect with other neurons. These actions modify \\ the release of both glutamate and GABA (gamma amino butyric acid) within \\ various brain circuits.
}

\section{Take-Home Points}

- Like most known antidepressants, vortioxetine inhibits the serotonin (5HT) transporter (SERT).

- Unlike most known antidepressants, vortioxetine targets numerous additional $5 \mathrm{HT}$ receptors: $5 \mathrm{HT} 1 \mathrm{~A}, 5 \mathrm{HT} 1 \mathrm{~B}$ $5 \mathrm{HT} 1 \mathrm{D}, 5 \mathrm{HT} 3$, and $5 \mathrm{HT7}$ receptors.

- These additional pharmacologic actions not only enhance the release of $5 \mathrm{HT}$ compared to blocking SERT alone, but also modify the release of numerous additional neurotransmitters.

- Specifically, vortioxetine's pharmacologic actions on 5HT receptors - unique compared to any other antidepressant-enhance the release of glutamate and inhibit the release of GABA (gamma amino butyric acid) from downstream neurons in various brain circuits such as the prefrontal cortex and hippocampus.

Vortioxetine is a "multimodal" agent that simultaneously acts at 6 pharmacologic targets with 3 modes of action (Figure 1$)^{1-4}$ :

1. Inhibition of the serotonin transporter or SERT

2. Actions at several G-protein linked receptors (agonist actions at 5HT1A receptors, partial agonist actions at 5HT1B receptors, antagonist actions at 5HT1D and 5HT7 receptors)

3. Inhibition of a ligand-gated ion channel (the 5HT3 receptor)

Although vortioxetine has a complex pharmacologic mechanism of action, the combined effects of all actions can be conceptualized more simply by how they alter the downstream release of numerous neurotransmitters. We have previously described the mechanisms whereby vortioxetine's actions at 5HT receptors work together to enhance the release of $5 \mathrm{HT} .^{5}$ Here we describe how vortioxetine alters the downstream release of both glutamate and GABA from the prefrontal cortex and hippocampus. An explanation of vortioxetine's actions that enhance the release of dopamine, norepinephrine, acetylcholine, and histamine are discussed in other Brainstorms articles. ${ }^{6,7}$

\section{Modes and Nodes}

Actions of neurotransmitters, drugs, and psychiatric illnesses can all be understood not only within a "microcircuit" — eg, a connection between a presynaptic $5 \mathrm{HT}$ neuron and a postsynaptic site-but also within "macrocircuits," eg, where serotonergic neurons are part of a neuronal network that connects many neurons with each other. ${ }^{5-9}$ The sites where neurons connect 


\section{BRAINSTORMS—Clinical Neuroscience Update}

Figure 1. Icon of vortioxetine showing its 6 pharmacologic mechanisms. Highlighted here are the 4 actions principally linked to its hypothesized enhancement of glutamate release. Increased firing of pyramidal neurons of the prefrontal cortex and hippocampus hypothetically arises from the combination of SERT inhibition, 5HT1A agonism, 5HT1B partial agonism, and 5HT3 antagonism.

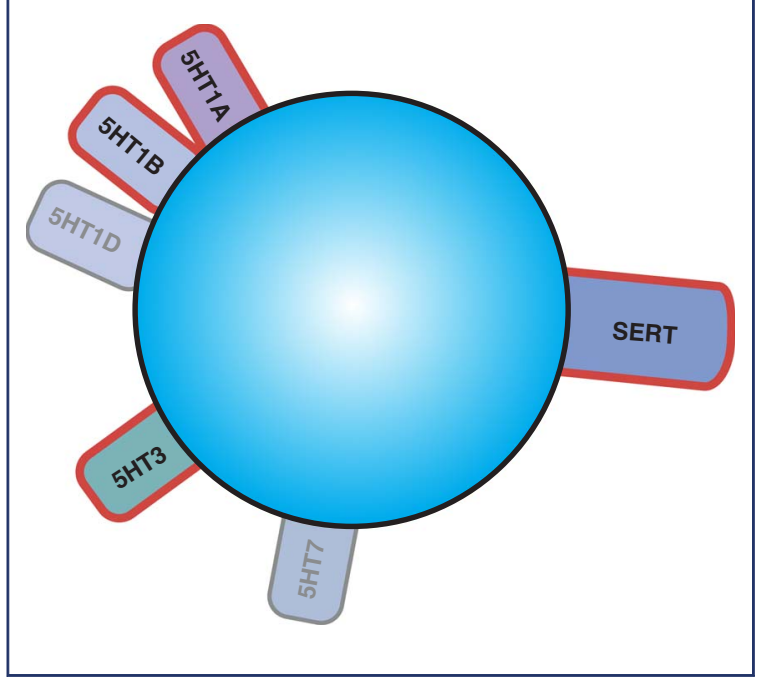

with each other are also called the "nodes" of a neuronal network. ${ }^{8,9}$ Two important sets of nodes that are uniquely distributed in various brain regions include the connections that 5HT neurons make with glutamate and GABA neurons ${ }^{10-14}$ (Figures 2 and 3). These connections allow 5HT to regulate downstream release of glutamate and GABA, with both direct effects on glutamatergic pyramidal neuron firing (Figure 2) and indirect effects on pyramidal neuron firing via modulating GABA neurotransmission of inhibitory cortical interneurons (Figure 3). ${ }^{10-14}$

Abnormal connectivity of brain circuits is theorized to cause symptoms of psychiatric disorders such as depression, and psychotropic drugs hypothetically reduce these symptoms by changing this connectivity, thus improving the efficiency of information processing in specific brain circuits. ${ }^{10,15,16}$ Since there are numerous symptoms in any given psychiatric condition, it is likely that there are numerous networks with altered connectivity involved in every psychiatric disorder. ${ }^{15,16}$ Psychopharmacologic agents that can change more than one neurotransmitter's release in more than one site (ie, multiple modes of action at multiple nodes within brain networks) theoretically have the possibility to change multiple symptoms linked to multiple circuits. ${ }^{4,15,16}$ Thus, it is useful to understand the net effect of the multiple simultaneous actions of
Figure 2. Direct regulation of glutamate release in the prefrontal cortex and hippocampus by $5 \mathrm{HT}$. This figure shows how glutamate release is regulated directly by $5 \mathrm{HT}$ actions on pyramidal neurons. Release of 5HT at apical dendrites of pyramidal neurons can be either excitatory at 5HT2C, 5HT4, 5HT6, or 5HT7 receptors or inhibitory at $5 \mathrm{HT} 5$ receptors (shown at the top of the figure). A key excitatory $5 \mathrm{HT}$ receptor is also the $5 \mathrm{HT} 2 \mathrm{~A}$ receptor. A key inhibitory 5HT receptor is the 5HT1A receptor. The net actions of 5HT at all these sites regulate the final common pathway of glutamate release (shown at the bottom of the figure), which in turn regulates downstream release of numerous neurotransmitters including DA, NE, ACh, $\mathrm{HA}$, and 5HT.

Direct Regulation of Glutamate Release by $5 \mathrm{HT}$

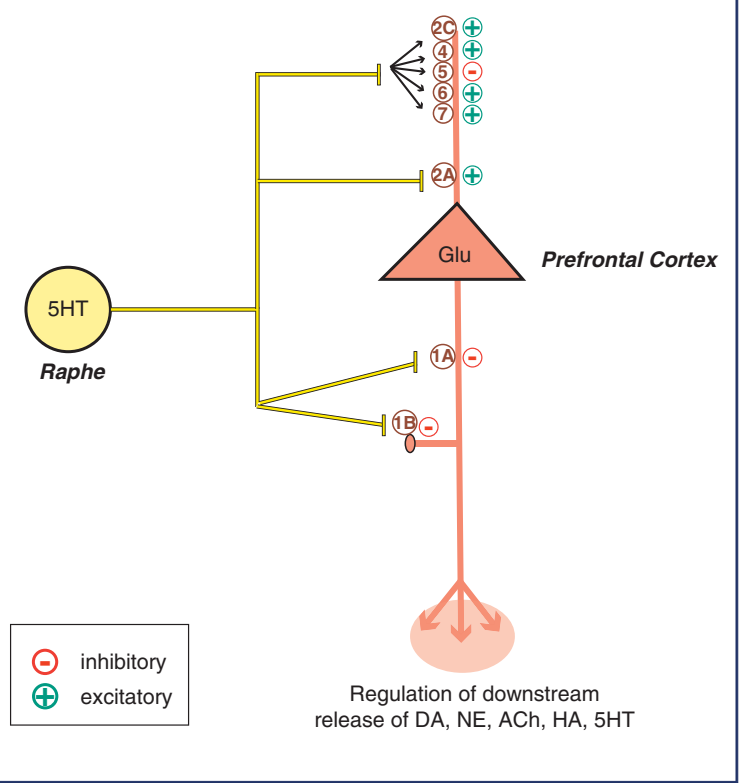

vortioxetine on downstream release of both glutamate and GABA in order to gain insight into its pharmacologic mechanism of therapeutic action in improving mood, cognition, and other symptoms of major depressive disorder.

\section{HT Neuronal Connections to Glutamate and GABA Neurons in the Prefrontal Cortex and Hippocampus}

5HT neurons project widely throughout the brain and notably to the prefrontal cortex and hippocampus and interact there with many glutamate and GABA neurons. ${ }^{10-14}$ The prefrontal cortex and hippocampus are hypothesized to be the sites of critical nodes within malfunctioning brain circuits responsible for various symptoms of major depressive disorder, from cognitive 


\section{BRAINSTORMS -Clinical Neuroscience Update}

Figure 3. Indirect regulation of glutamate release in the prefrontal cortex and hippocampus by $5 \mathrm{HT}$ acting via

GABA interneurons. This figure shows how glutamate release from pyramidal neurons is regulated indirectly by 5HT acting through two types of interneurons. At the top is shown a GABA interneuron that does not stain for parvalbumin, and is regular spiking, late spiking, or bursting in its firing pattern. Release of $5 \mathrm{HT}$ at this population of GABA neurons can both inhibit them via 5HT1A receptors, or excite them via either 5HT2A or 5HT3 receptors. Below the first GABA neuron is another class of GABA interneuron that does stain for parvalbumin and is fast spiking in firing pattern. The $5 \mathrm{HT}$ receptors that are populated on this second type of GABA interneuron include inhibitory 5HT1A receptors, inhibitory 5HT1B receptors, and excitatory 5HT2A receptors. When GABA is released after stimulation of any excitatory 5HT receptor, glutamate release is inhibited. When GABA release is blocked by $5 \mathrm{HT}$ acting at any inhibitory $5 \mathrm{HT}$ receptor, glutamate release is disinhibited (ie, enhanced). The net actions of $5 \mathrm{HT}$ at all these sites regulate the final common pathway of glutamate release (shown at the bottom of the figure), which in turn regulates downstream release of numerous neurotransmitters including DA, NE, $\mathrm{ACh}, \mathrm{HA}$, and 5HT.

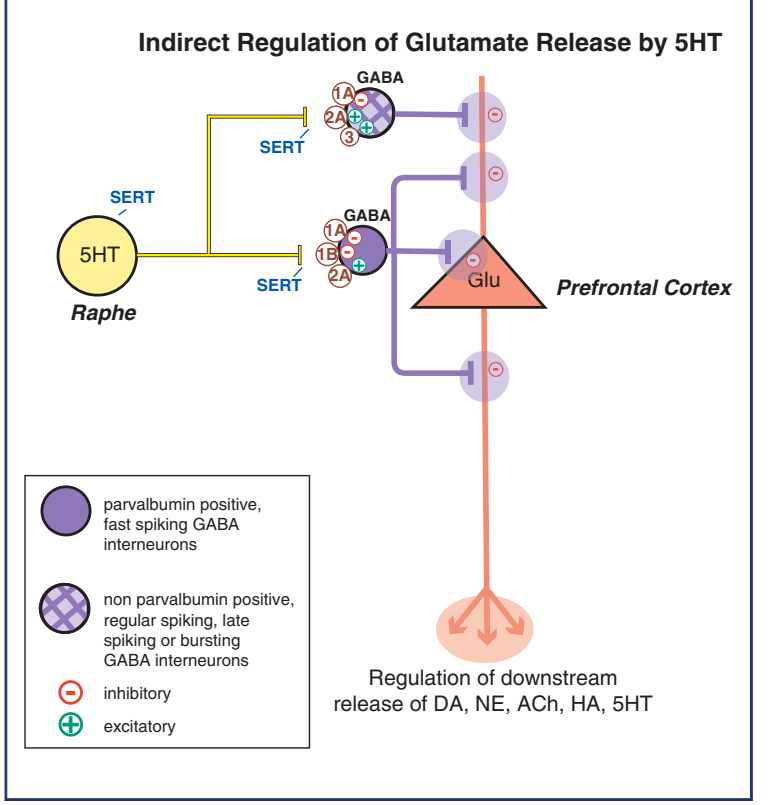

functions such as learning, working memory, attention, and behavioral flexibility, to mood and other emotions. ${ }^{15-17}$ 5HT neurons terminate both directly upon glutamatergic pyramidal neurons (Figure 2) and indirectly upon GABAergic inhibitory interneurons that in turn terminate upon pyramidal neurons (Figure 3). ${ }^{10-14,18}$ What results is an elegant array of excitatory and inhibitory actions of the neuronal network of the prefrontal cortex.

Specifically, 5HT neurons act directly at glutamate pyramidal neurons and can be both excitatory (eg, at 5HT2A, 5HT2C, 5HT4, 5HT6, and 5HT7 receptors) ${ }^{19-37}$ and inhibitory (at 5HT1A, 5HT5, and possibly postsynaptic 5HT1B heteroreceptors) ${ }^{32-37}$ (Figure 2). Additional control of glutamate output from pyramidal neurons is provided by multiple 5HT receptor actions on inhibitory GABAergic interneurons $^{19-37}$ (Figure 3). One major population of GABAergic interneurons is "fast spiking" and contains inhibitory 5HT1A receptors, and excitatory 5HT2A and 5HT3 receptors ${ }^{19-37}$ (Figure 3). These so-called "basket" and "chandelier" interneurons stain for the calcium binding protein parvalbumin and each innervate 200-1000 pyramidal cells. Basket cells comprise about half of non-pyramidal cells in the cortex..$^{10-14,18} \mathrm{~A}$ second major population of GABAergic interneurons stains for different neurochemical markers (eg, calbindin, calretinin, cholecystokinin, vasoactive intestinal peptide, somatostatin, and/or neuropeptide Y) and fire with electrical activity that is regular spiking, late spiking, or bursting in character ${ }^{10-14,18}$ (Figure 3). They contain inhibitory postsynaptic 5HT1A and possibly inhibitory postsynaptic 5HT1B heteroreceptors, as well as excitatory $5 \mathrm{HT} 2 \mathrm{~A}$ receptors ${ }^{19-37}$ (Figure 3).

With so many ways to stimulate and to inhibit the glutamate neuron, and with some 5HT receptors doing the opposite thing to glutamate release indirectly via GABA neurons that they do to glutamate release directly upon pyramidal neurons, the question arises as to which action of 5HT upon glutamate release will prevail at any one time. Analysis of the neuronal macrocircuitry (Figures 2 and 3) suggests that 5HT can induce mixed effects both upon glutamate (Figure 2) and GABA (Figure 3) in the prefrontal cortex and hippocampus. ${ }^{19-37}$ The net effects of 5HT upon glutamate will therefore depend upon the regional and cellular expression patterns of 5HT receptor subtypes, the density of $5 \mathrm{HT}$ receptors, and the local concentration of 5HT. 5HT affinity is different for its various receptors, eg, 2- to 6-fold higher for 5HT1A receptors over 5HT2A receptors and even higher over 5HT3 receptors. ${ }^{18-20,38-45}$ Thus, low 5HT concentrations in a given location within a neuronal network will skew the effects of 5HT release there more heavily toward inhibition from 5HT1A receptors, with excitation mediated by 5HT2A and 5HT3 receptors becoming more prominent as 5HT concentrations increase. 5HT seems to be well positioned to act as a neuromodulator whose function could be to maintain homeostasis in the 
brain, fine-tuning the glutamate in prefrontal cortical networks up or down as needed and thus acting as a "buffer" to "normalize" output of pyramidal neurons. In other words, keeping glutamatergic pyramidal neurons "in tune" (neither too quiet nor too excited) could be the task of $5 \mathrm{HT}$ acting in a coordinated manner at all of its receptors.

\section{Effects of Antidepressants on Glutamate Release and Neuronal Firing of Pyramidal Neurons in Prefrontal Cortex and Hippocampus}

Antidepressants that block 5HT reuptake (serotonin transporter or SERT inhibitors) such as SSRIs (selective serotonin reuptake inhibitors) increase $5 \mathrm{HT}$ concentrations everywhere there are 5HT nerve terminals. 5HT release is mitigated by $5 \mathrm{HT}^{\prime}$ 's stimulation of inhibitory 5HT autoreceptors on 5HT neurons as discussed in an earlier article. ${ }^{5,17}$ The net effect of acute elevations of 5HT upon glutamate release by SSRIs would therefore appear to be mixed, with both excitatory and inhibitory effects that largely cancel themselves out. ${ }^{46,47}$ Studies of long-term administration of SSRIs in animals, however, suggest a reduction of pyramidal neuron activity, and thus of glutamate release, possibly due to the pattern of desensitization of some serotonin receptor systems. ${ }^{46,47}$ In disease states such as depression with hypothetically dysregulated circuits of emotions and cognition, therapeutic actions of antidepressants may require instead enhanced pyramidal neuron firing in the prefrontal cortex or hippocampus in order to change the connectivity of one brain region to another and to rebalance the information processing of a neuronal network. For example, the actions of the novel rapid-acting antidepressant ketamine on mood are associated with increased downstream glutamate release. ${ }^{4-50}$ Also, enhanced neuronal output from pyramidal neurons promotes glutamate dependent neuronal plasticity and long-term potentiaion, key components of cognition and memory, and possibly necessary actions to improve cognitive symptoms of depression. ${ }^{51-53}$

Although long-term studies have not been reported, vortioxetine-in contrast to SSRIs-acutely enhances firing of pyramidal neurons, ${ }^{54}$ presumably due to its additional receptor actions combined with SERT inhibition (Figure 4). Potent antagonism of vortioxetine at $5 \mathrm{HT} 3$ receptors may be the most relevant action in this regard, as this removes an important source of 5HT-mediated inhibition from a population of GABA interneurons, thus disinhibiting pyramidal neurons (Figures 3 and 4 ). ${ }^{54}$ HT1A agonism by vortioxetine
Figure 4. Vortioxetine enhances glutamate release. Not only does vortioxetine block SERTs the same as SSRIs, but it also has numerous direct receptor actions that diminish GABA inhibition at both populations of GABA interneurons. At the top, agonist actions at 5HT1A receptors inhibit GABA release; also, antagonist actions at 5HT3 receptors inhibit GABA release. At the second GABA neuron below, agonist actions at 5HT1A receptors and possibly partial agonist actions at $5 \mathrm{HT} 1 \mathrm{~B}$ receptors inhibit GABA release from this interneuron. Combining what

happens at both GABA neurons, glutamate release downstream is disinhibited. Perhaps the most robust of these actions is the blockade of 5HT3 receptors. When glutamate release is enhanced, it can lead to the enhanced downstream release of numerous neurotransmitters including DA, NE, ACh, HA, and 5HT.

Indirect Regulation of Glutamate Release by $5 \mathrm{HT}$

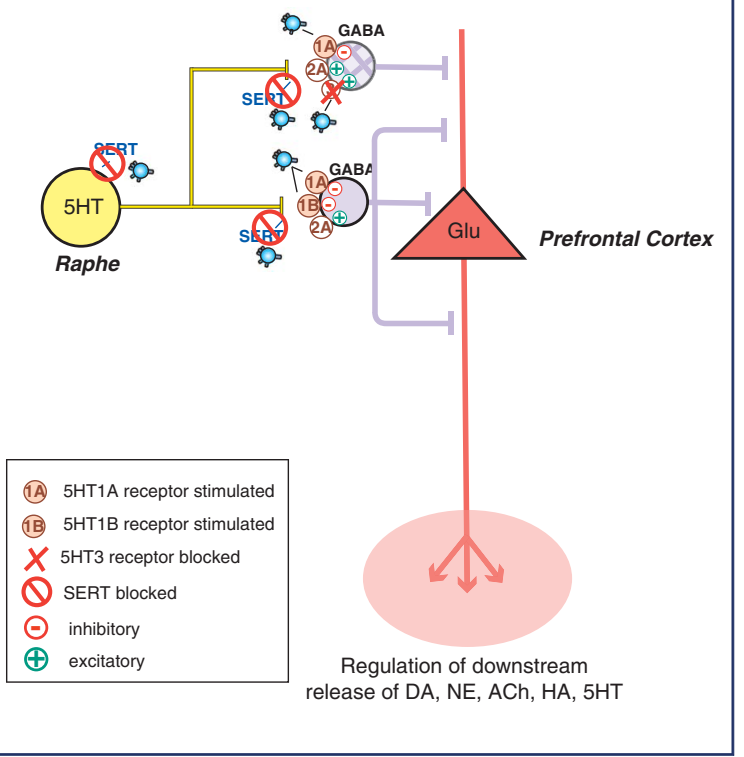

inhibits both major subpopulations of GABA interneurons, further disinhibiting pyramidal neurons (Figures 3 and 4). Partial agonist actions of vortioxetine at presynaptic 5HT1B inhibitory autoreceptors on 5HT neurons should lead to greater $5 \mathrm{HT}$ release, and partial agonist actions at 5HT1B inhibitory postsynaptic heteroreceptors on glutamatergic cortical nerve terminals may directly enhance glutamate release (Figure 2). ${ }^{55,56}$ Weaker actions of vortioxetine at $5 \mathrm{HT7}$ receptors and the relative lack of 5HT1D receptors in prefrontal cortex make vortioxetine's actions at these receptors in cortical and hippocampal networks unclear. The result of all receptor actions of vortioxetine can hypothetically explain why glutamate output is 


\section{BRAINSTORMS -Clinical Neuroscience Update}

increased (Figure 4). These actions can potentially explain why there is a differential effect of vortioxetine compared to SSRIs in the hippocampus and prefrontal cortex, presumably due to multiple actions at 5HT receptors, compared to SERT inhibitors such as SSRIs that stimulate every $5 \mathrm{HT}$ receptor in every site.

\section{Summary}

In summary, vortioxetine enhances the output of glutamatergic pyramidal neurons and reduces the output of GABAergic interneurons in the prefrontal cortex and hippocampus. Blockade of 5HT3 receptors and SERTs while stimulating 5HT1A receptors and (partially) 5HT1B receptors at nodes within neural networks where 5HT neurons connect with glutamate and GABA neurons may account for these changes in neuronal activity. Improving information processing within neuronal networks could hypothetically result from these receptor actions and be the mechanism that leads to improvement in the symptoms of depression by vortioxetine. Enhanced release of glutamate from increased pyramidal neuron activity, which is unique for vortioxetine compared to SSRIs, could also enhance long-term potentiation, neuronal plasticity, and memory formation and could potentially explain not only the antidepressant/mood actions of vortioxetine but also its unique procognitive actions compared with other antidepressants.

\section{References:}

1. Mørk A, Pehrson A, Brennum LT, et al. Pharmacological effects of Lu AA21004: a novel multimodal compound for the treatment of major depressive disorder. J Pharmacol Exp Ther 2012; 340(3): 666-675.

2. Bang-Andersen $B$, Ruhland $\mathrm{T}$, Jorgensen $\mathrm{M}$, et al. Discovery of 1-[2-(2,4-dimethylphenylsulfanyl)phenyl]piperazine (Lu AA21004): a novel multimodal compound for the treatment of major depressive disorder. J Med Chem. 2011; 54(9): 3206-3221.

3. Pehrson AL, Cremers T, Bétry C, et al. Lu AA21004, a novel multimodal antidepressant, produces regionally selective increases of multiple neurotransmitters-a rat microdialysis and electrophysiology study. Eur Neuropsychopharmacol. 2013; 23(2): 133-145.

4. Sanchez C, Asin KE, Artigas F. Vortioxetine, a novel antidepressant with multimodal activity: review of preclinical and clinical data. Pharmacol Ther. 2015; 145: 43-57.

5. Stahl SM. Modes and nodes explain the mechanism of action of vortioxetine, a multi-modal agent (MMA): enhancing serotonin release by combining serotonin (5HT) transporter inhibition with action at 5HT receptors (5HT1A, 5HT1B, 5HT1D, 5HT7 receptors). CNS Spectr. 2015; 20(2): 93-97.

6. Stahl SM. Modes and nodes explain the mechanism of action of vortioxetine, a multi-modal agent (MMA): enhancing downstream release of neurotransmitters by blocking $5 \mathrm{HT} 3$ receptors. CNS Spectr. In press.
7. Stahl SM. Modes and nodes explain the mechanism of action of vortioxetine, a multi-modal agent (MMA): actions at serotonin receptors may enhance downstream release of four pro-cognitive neurotransmitters. CNS Spectr. In press.

8. Kuman A, Vlachos I, Aersen A, Boucsein C. Challenges of understanding brain function by selective modulation of neuronal subpopulations. Trends Neurosci. 2013; 36(10): 579-586.

9. Warren JD, Roher JD, Schott JM, Fox NC, Hardy J, Rossor MN. Molecular nexopathies: a new paradigm of neurodegenerative disease. Trends Neurosci. 2013; 36(10): 561-569.

10. Pehrson AL, Sanchez C. Serotonergic modulation of glutamate neurotransmission as a strategy for treating depression and cognitive dysfunction. CNS Spectr. 2014; 19(2): 121-133.

11. Puig MV, Gulledge AT. Serotonin and prefrontal cortex function: neurons, networks, and circuits. Mol Neurobiol. 2011; 44(3): 449-464.

12. Kubota Y. Untangling GABAergic wiring in the cortical microcircuit. Curr Opin Neurobiol. 2014; 26: 7-14.

13. Adesnik H, Scanziani M. Lateral competition for cortical space by layer-specific horizontal circuits. Nature. 2010; 464(7292): 1155-1160.

14. Gottlieb JP, Keller A. Intrinsic circuitry and physiological properties of pyramidal neurons in rat barrel cortex. Exp Brain Res. 1997; 115(1): 47-60.

15. Insel $\mathrm{T}$, Cuthbert $\mathrm{B}$, Garvey $\mathrm{M}$, et al. Research domain criteria (RDoC): toward a new classification framework for research on mental disorders. Am J Psychiatry. 2010; 167(7): 748-751.

16. Stahl SM. The last diagnostic and statistical manual (DSM): replacing our symptom-based diagnoses with a brain circuit-based classification of mental illnesses. CNS Spectr. 2013; 18(2): 65-68.

17. Stahl SM. Stahl's Essential Psychopharmacology, 4th ed. Cambridge, UK: Cambridge University Press; 2013.

18. Celada P, Puig MV, Artigas F. Serotonin modulation of cortical neurons and networks. Front. Integr Neurosci. 2013; 7: 25.

19. Cornea-Hebert V, Riad M, Wu C, Singh SK, Descarries L. Cellular and subcellular distribution of the serotonin 5-HT2A receptor in the central nervous system of adult rat. J Comp Neurol. 1999; 409(2): 187-209.

20. Puig MV, Watakabe A, Ushimaru M, Yamamori T, Kawaguchi $Y$ Serotonin modulates fast-spiking interneuron and synchronous activity in the rat prefrontal cortex through 5-HT1A and 5-HT2A receptors. J Neurosci. 2010; 30(6): 2211-2222.

21. Abramowski D, Rigo M, Duc D, Hoyer D, Staufenbiel M. Localization of the 5-hydroxytryptamine2C receptor protein in human and rat brain using specific antisera. Neuropharmacol. 1995; 34(12): 1635-1645.

22. Feng J, Cai $X$, Zhao J, Yan Z. Serotonin receptors modulate GABA(A) receptor channels through activation of anchored protein kinase $\mathrm{C}$ in prefrontal cortical neurons. J Neurosci. 2001; 21(17): 6502-6511.

23. Puig MV, Celada P, Diaz-Mataix L, Artigas F. In vivo modulation of the activity of pyramidal neurons in the rat medial prefrontal cortex by 5 -HT2A receptors: relationship to thalamocortical afferents. Cereb Cortex. 2003; 13(8): 870-882.

24. Vilaro MT, Cortes R, Mengod G. Serotonin 5-HT4 receptors and their mRNAs in rat and guinea pig brain: distribution and effects of neurotoxic lesions. J Comp Neurol. 2005; 484(4): 418-439.

25. Oliver KR, Kinsey AM, Wainwright A, Sirinathsinghji DJ. Localization of 5-HT(5A) receptor-like immunoreactivity in the rat brain. Brain Res. 2000; 867(1-2): 131-142.

26. Goodfellow NM, Bailey CD, Lambe EK. The native serotonin 5-HT (5A) receptor: electrophysiological characterization in rodent cortex and 5-HT(1A)-mediated compensatory plasticity in the knock-out mouse. J Neurosci. 2012; 32(17): 5804-5809.

27. Gerard C, Martres MP, Lefevre K, et al. Immuno-localization of serotonin 5-HT6 receptor-like material in the rat central nervous system. Brain Res. 1997; 746(1-2): 207-219. 


\section{BRAINSTORMS - Clinical Neuroscience Update}

28. Marazziti D, Baroni S, Pirone A, et al. Serotonin receptor of type 6 (5-HT6) in human prefrontal cortex and hippocampus post-mortem: an immunohistochemical and immunofluorescence study. Neurochem Int. 2013; 62(2): 182-188.

29. Neumaier JF, Sexton TJ, Yracheta J, Diaz AM, Brownfield M. Localization of 5-HT(7) receptors in rat brain by immunocytochemistry, in situ hybridization, and agonist stimulated cFos expression. J Chem Neuroanat. 2001; 21(1): 63-73.

30. Tokarski K, Zahorodna A, Bobula B, Hess G. 5-HT7 receptors increase the excitability of rat hippocampal CA1 pyramidal neurons. Brain Res. 2003; 993(1-2): 230-234.

31. Tokarski K, Kusek M, Hess G. 5-HT7 receptors modulate GABAergic transmission in rat hippocampal CA1 area. J Physiol Pharmacol. 2011; 62(5): 535-540.

32. Amargos-Bosch M, Bortolozzi A, Puig MV, et al. Co-expression and in vivo interaction of serotonin1 $\mathrm{A}$ and serotonin2A receptors in pyramidal neurons of prefrontal cortex. Cereb Cortex. 2004; 14(3): 281-299.

33. Gartside SE, Hajos-Korcsok E, Bagdy E, Harsing LG Jr, Sharp T, Hajos M. Neurochemical and electrophysiological studies on the functional significance of burst firing in serotonergic neurons. Neurosci. 2000; 98(2): 295-300.

34. Hajos M, Gartside SE, Varga V, Sharp T. In vivo inhibition of neuronal activity in the rat ventromedial prefrontal cortex by midbrain-raphe nuclei: role of 5-HT1A receptors. Neuropharmacology. 2003; 45(1): 72-81.

35. de Groote L, Klompmakers AA, Olivier B, Westenberg HG. An evaluation of the effect of NAS-181, a new selective 5-HT(1B) receptor antagonist, on extracellular 5-HT levels in rat frontal cortex. Naunyn Schmiedebergs Arch Pharmacol. 2003; 367(2): 89-94.

36. Tanaka E, North RA. Actions of 5-hydroxytryptamine on neurons of the rat cingulate cortex. J Neurophysiol. 1993; 69(5): 1749-1757.

37. Egeland M, Warner-Schmidt J, Greengard P, Svenningsson P. Co-expression of serotonin 5-HT(1B) and 5-HT(4) receptors in p11 containing cells in cerebral cortex, hippocampus, caudateputamen and cerebellum. Neuropharmacology. 2011; 61(3): 442-450.

38. Morales M, Battenberg E, de Lecea L, Bloom FE. The type 3 serotonin receptor is expressed in a subpopulation of GABAergic neurons in the rat neocortex and hippocampus. Brain Res. 1996; 731 (1-2): 199-202.

39. Gehlert DR, Gackenheimer SL, Wong DT, Robertson DW. Localization of 5-HT3 receptors in the rat brain using [3H] LY278584. Brain Res. 1991; 553(1): 149-154.

40. Morales M, Battenberg E, Bloom FE. Distribution of neurons expressing immunoreactivity for the 5HT3 receptor subtype in the rat brain and spinal cord. J Comp Neurol. 1998; 402(3): 385-401.

41. Vilaro MT, Cortes R, Mengod G. Serotonin 5-HT4 receptors and their mRNAs in rat and guinea pig brain: distribution and effects of neurotoxic lesions. J Comp Neurol. 2005; 484(4): 418-439.
42. Pompeiano M, Palacios JM, Mengod G. Distribution and cellular localization of mRNA coding for 5-HT1A receptor in the rat brain correlation with receptor binding. J Neurosci. 1992; 12(2): 440-453.

43. Bruinvels AT, Palacios JM, Hoyer D. Autoradiographic characterisation and localisation of 5-HT1D compared to 5-HT1B binding sites in rat brain. Naunyn Schmiedebergs Arch Pharmacol. 1993; 347(6): 569-582

44. Sari $\mathrm{Y}$, Lefevre K, Bancila M, et al. Light and electron microscopic immunocytochemical visualization of 5-HT1B receptors in the rat brain. Brain Res. 1997; 760(1-2): 281-286.

45. Sari Y, Miquel MC, Brisorgueil MJ, et al. Cellular and subcellular localization of 5-hydroxytryptamine1B receptors in the rat central nervous system: immunocytochemical, autoradiographic and lesion studies. Neuroscience. 1999; 88(3): 899-915.

46. Gronier BS, Rasmussen K. Electrophysiological effects of acute and chronic olanzapine and fluoxetine in the rat prefrontal cortex. Neurosci Lett. 2003; 349(3): 196-200.

47. Ceci A, Fodritto F, Borsini F. Repeated treatment with fluoxetine decreases the number of spontaneously active cells per track in frontal cortex. Eur J Pharmacol. 1994; 271(1): 231-234.

48. Stahl SM. Mechanism of action of ketamine. CNS Spectr. 2013; 18(4): 171-174.

49. Li N, Lee B, Liu RJ, et al. mTOR-dependent synapse formation underlies the rapid antidepressant effects of NMDA antagonists. Science. 2010; 329(5994): 959-964.

50. Maeng S, Zarate CA, Du J, et al. Cellular mechanisms underlying the antidepressant effects of ketamine: role of alpha-amino-3hydroxy-5-methylisoxazole-4-propionic acid receptors. Biol Psychiatry. 2007; 63(4): 349-352.

51. Riedel G, Platt B, Micheau J. Glutamate receptor function in learning and memory. Behav Brain Res. 2003; 140(1-2): 1-47.

52. Manji HK, Quiroz JA, Sporn J, et al. Enhancing neuronal plasticity and cellular resilience to develop novel, improved therapeutics for difficult-to-treat depression. Biol Psychiatry. 2003; 53(8): 707-742.

53. Muller D, Joly M, Lynch G. Contributions of quisqualate and NMDA receptors to the induction and expression of LTP. Science. 1988; 242(4886): 1694-1697.

54. Bétry C, Pehrson AL, Etiévant A, Ebert B, Sánchez C, Haddjeri N. The rapid recovery of $5 \mathrm{HT}$ cell firing induced by the antidepressant vortioxetine involves 5 HT3 receptor antagonism. Int J Neuropsychopharmacol. 2013; 16(5): 1115-1127.

55. Peddie CJ, Davies HA, Colyer FM, Stewart MG, Rodriguez JJ. Dendritic colocalisation of serotonin1B receptors and the glutamate NMDA receptor subunit NR1 within the hippocampal dentate gyrus: an ultrastructural study. J Chem Neuroanat. 2008; 36(1): 17-26.

56. Peddie CJ, Davies HA, Colyer FM, Stewart MG, Rodriguez JJ. A subpopulation of serotonin $1 \mathrm{~B}$ receptors colocalize with the AMPA receptor subunit GluR2 in the hippocampal dentate gyrus. Neurosci Lett. 2010; 485(3): 251-255. 